\title{
A review of spirituality as applied to nursing
}

\author{
Aru Narayanasamy* \\ Faculty of Medicine and Health Sciences, School of Nursing (undergraduate division), University of Nottingham, A Floor, Queens \\ Medical Centre, Nottingham NG7 2UH, UK
}

Received 12 January 1998; received in revised form 1 August 1998; accepted 1 December 1998

\begin{abstract}
In this paper a review of spirituality as applied to nursing is carried out. In doing so, it is shown that the holistic understanding of spirituality has been derived almost exclusively from the Christian theological tradition. Whilst recognizing the importance of this tradition, the relatively unknown element, that is, the biological basis of spirituality as advanced by empirical research on spiritual awareness is brought to the debate in this review. Following the review, an operational definition of spirituality embracing its biological roots is provided to highlight its significance to nursing. (C) 1999 Elsevier Science Ltd. All rights reserved.
\end{abstract}

Keywords: Spirituality as an holistic dimension; Christian theological tradition; Biological basis of spirituality; Operational definition of spirituality

\section{Introduction}

In nursing and related health care literature, nurses and other professionals usually refer to spirituality in relation to an holistic view of the human person. The literature review that follows will show that the holistic understanding of spirituality has been derived almost exclusively from the Christian theological tradition. The element that I shall add is reference to the biological root of spirituality as hypothesized by Hardy (1979) and Hay (1996). They suggest that spirituality is natural to the human species and has evolved because it has biological survival value. It is argued in this paper that the claim that holistic nursing embraces the spiritual dimension is flawed thinking due to the lack of consideration to the biological root in its definition of spirituality. The emerging empirical studies suggest that almost half of British adult of population believe

* Tel.: + 44-115-924-9924 ext. 42353 . they have been spiritually or religiously aware, at least from time to time (Hay and Morisy, 1978; Hardy, 1979; Lewis, 1985). These studies suggest that spiritual awareness may be a human universal that has evolved because it has a biological survival value. The flaw in the claim about holistic nursing is due to a lack of awareness in the nursing literature about the biological root of spirituality. The purpose of this paper is to bring to focus this biological understanding related to spirituality. It is anticipated that this paper would stimulate further debate on the spiritual dimension of nursing.

\section{Spirituality as an holistic notion}

Spirituality is a multidimensional word that defies a single definition. In the health context, spirituality is viewed as an aspect of the holistic understanding of the person (Stallwood, 1981; Shelley and Fish, 1988; Carson, 1989). The holistic notion holds the premise 


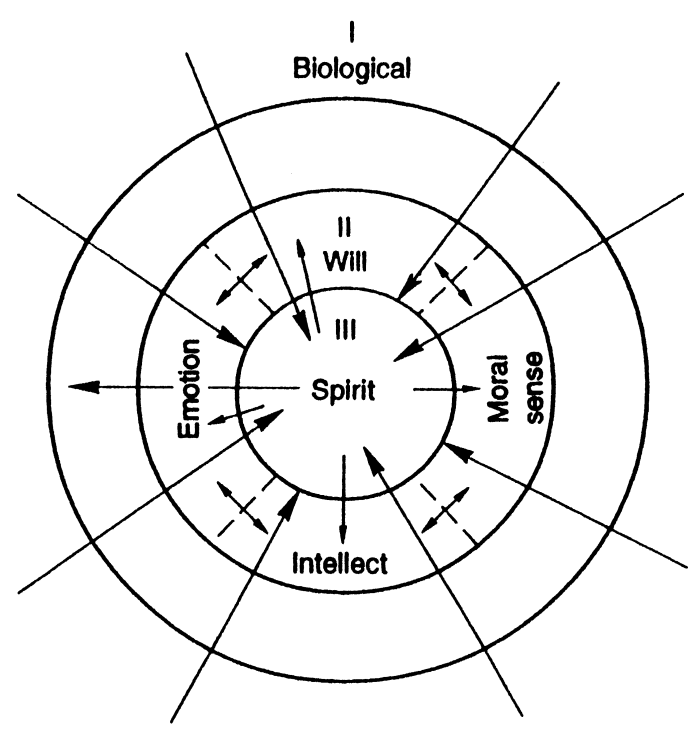

Fig. 1. Conceptual model of nature of person.

that an individual as a whole person is the integration of body, mind and spirit, which are inseparable.

The term holism originated from the work of the South African statesman and philosopher J.Chr. Smutts (1926) in the early part of this century. Holism relates to the study of whole organism or whole systems, its spelling derived from the Greek word 'holos' meaning 'whole'. In applying it to the Western health care context, it may be seen as an approach that incorporates the interrelationships between all aspects of bodily functions and psycho-social functions in a sort of multifaceted approach to the human being.

Lazlo (1972) develops further the notion of holism. He identifies two kinds of holism. Firstly, in a narrower sense, holism represents the human organism as a self-contained living system whose components are interconnected and interdependent. Secondly, in a broader sense, holism depicts the human organism as an integral living system as part of larger systems. In the broader sense, an holistic approach would see a functioning person as a totality or a total functioning entity interacting with his/her environment. In this sense, not only is the individual organism in continual interaction with its physical and social environment, but it is also constantly acting upon and being acted upon the environment.

As previously suggested, holism refers to a perspective that an individual as a whole person is the integration made of body, mind and spirit, which are inseparable. According to this, a person who behaves with holistic understanding is one who experiences a harmonious balance between these components. With regard to spirituality, holism emphasizes that a continued harmonious interaction between the innermost core (spirit), the mind and body is required to maintain an individual's health.

Stallwood (1981) illustrates the holistic notion of spirituality in the conceptual model of the nature of a person (Fig. 1). Her model is a clear illustration of a person's wholeness. She explains that the individual, as an integrated whole, is composed of the body, mind (psychosocial) and spirit, and that these components are dynamically woven together, one part affecting and being affected by the other parts. The figure below depicts an adaptation of a model developed by Stallwood as an illustration of a person's wholeness.

The outer circle represents the biological nature of an individual; the middle circle depicts the mind as having four elements - will, emotion, intellect and moral sense; the smallest, innermost circle represents the spiritual nature. Alteration to any one of three components affects the two other components and, ultimately, the whole person.

Although the diagram may remind us of Descartes' dualism (Warburton, 1992; Popkin and Stroll, 1993), that is, belief in a distinct split between the body and mind or spirit, in my view Stallwood is not implying such a dualism. However, it is worth noting that the biblical notion of spirituality gained further hold since the seventeenth century following Rene Descarte's metaphysics of the three basic components in the universe - God, mind and matter. The assumption that the spiritual element was distinguishable from the material or bodily became sustainable. According to Descartes' God is the creative substance who made the mind and matter. The essential property of the mind is that it thinks, whereas the essential property of matter is that it extends. All events related to the material or the mental realm is entirely dependent on the will of God, which orders and controls them. However, amongst contemporary philosophers of medicine there is a drift away from the dualism of Descartes' which led to an analytical and mechanistic approach to medicine. As a machine, isolated from mind/soul, the body could be broken down into its component parts. Such an approach led to major scientific and technological advances in medicine, from William Harvey's discovery of the circulatory system in 1648 to current research in genetic engineering. However, today the critical decisions individuals must face in health care as a result of these technological advances have brought about a focus on the spiritual dimension as part of a shift in an emphasis towards holistic health care.

Holism challenges Descartes' notion of the body as 'nothing but' a machine. It stresses the need to study the whole being and manner in which the body, mind and spirit interact, as seen in Stallwood's model. From this perspective, disturbance to the whole is evident in 
illness. In other words, in a crisis such as chronic illness where the body is affected by disease or pathological abnormalities, as part and parcel of that process, the person becomes spiritually distressed. In this regard Murray and Zentner (1989, p. 259) write:

The spiritual dimension tries to be in harmony with the Universe, strives for answers about the infinite, and comes into focus when the person faces emotional stress, physical illness or death.

There is a literature on nursing which attempts to provide an emphasis on spirituality, from this holistic perspective. Such literature describes spirituality or spiritual life as:

- the essence or life principle of person (Colliton, 1981);

- a sacred journey (Mische, 1982);

- the experience of the radical truth of things (Legere, 1984);

- giving meaning and purpose in life (Legere, 1984);

- a life relationship or a sense of connection with mystery, a higher power, God or Universe (Granstrom, 1985).

- as a belief that relates a person to the world (Soeken and Carson, 1987).

Because of its historical location within Western and Judeo-Christian culture, this literature usually attempts to settle on holistic definitions of spirituality which have a strong adherence to Christian theological tradition. It is also the case that the majority of nurses and patients in British hospitals have been reared in a culture which, though secularized, is permeated with Christian religious assumptions. Therefore, in the review that follows I have chosen to emphasize the influence of Christianity upon the definitions of spirituality and some of its limitations are discussed subsequently.

\section{Christian theological tradition}

Stoll (1989) and Shelley and Fish (1988) reflect a Christian theological influence in their descriptions of the spiritual dimension. Stoll $(1989$, p. 6) draws from the Book of Genesis (1:27) to describe a person's spirit as:

...an animating, intangible principle that gives life to the physical organism...[it] integrates and transcends all other dimension of the person... The literal breath of life.
Similarly, Shelley and Fish (1988, p. 3) use the Christian theological tradition in situating the concept of spirituality within an holistic context. However, these authors justify their holistic approach to nursing by stating

The person is a physically, psychologically, and spiritually integrated being, created to live in harmony with God, himself and others.

More recently, the spiritual dimension of nursing from a Christian theological tradition is explicit in the Bradshaw (1994) work. Bradshaw uses the Genesis account in the Bible (Genesis, 1:27) to advance the theological basis of a Christian understanding of spirituality. According to this account God created Man and Woman (humanity) in his image. Man and woman are unique and their nature is a unity, not a dualistic composition of physical body and spiritual soul as put forward by Descartes, but an entity in which the body finds expression in the whole.

Richardson (1969a) also highlights the significance of the Christian tradition in the broader context of caring. Richardson postulates that it is evident that the secularized world has inherited from Christian civilization, governed by this tradition the concept of the care of the sick and feeble by society as a whole. For, according to Richardson, it is this understanding which underpins human beings responses, albeit imperfectly, to Christ's call to love. It is responsible for reconciling scientific medicine and human compassion, as a consequence of the refusal to recognize a distinction between spiritual and physical affliction.

The Christian theological position on spirituality has an ethical impact on nursing in the following respects. Firstly, the ethic or the practical activity of the classical theological position features the love of God in the Gospel. It illustrates Jesus' great concern for all humanity, the weak and aged, as well as the young, healthy and attractive. Hebblewaite (1981, p. 135) provides a clear statement of the ethic (or practical activity) arising from the Christian theological tradition:

The subject matter of Christian ethics is human goodness and human community, as the lives of men and women are in fact conformed to Christ through the working of his Spirit. The proof of the theory lies in the practice. A study of the practical adequacy of Christian ethics would be a study of actual Christian lives, of saints and social reformers, of men and women who have shown the love of Christ in their protest at injustice and in caring for the poor, the sick and the dying, often in situations 
of utter hopelessness, at least by any purely human standard.

Secondly, the Christian theological position lays its emphasis on love. In regard to this, it proposes that humanity's freedom exists for the sake of love which is made possible through freedom (Berkhof, 1979). Freedom and love are part and parcel of humanity's renewal, the renewal that God works on humanity through his spirit.

Richardson (1969b) establishes that love is the essential characteristic of God's nature (1John 4:8,16) from which all human love is derivative (1John 4:19). Since human beings are created in God's image, love is therefore a natural and universal human feature. Nygren (1938), as cited by Bradshaw (1994), describes this love as 'agape' or Christian love, which implies more than love for the physical body of another.

According to Nygren, agape represents the supreme 'love' in the New Testament and signifies a concept of love as given unconditionally despite the unattractiveness or even repulsiveness of its object (man/woman such as the sinner). In contrast, eros is the love that is prompted by the attractive features of the loved one. Nygren explains that divine love is always agape, man/ woman's love is often limited to eros. Jesus is the exemplar who showed agape, in human form, providing the model for Christians, of self-giving love.

Karl Barth (1958, p. 752) contends that the love of God, agape, is the basis of all Christian love, but he disagrees with Nygren over the sharp distinction that he drew between agape and eros as shown above. In contrast, Barth believes that in the Christian life agape is the only sustainable love that eventually takes over and perfects eros. He portrays agape love as,

Love is a free action: self-giving of one to another without interest, intention or goal: the spontaneous self-giving of the one to the other just because the other is there and confronts him. It is not an action which has no ground or basis. The man engaged in it, the Christian, exists as and because God is his basis, and has disclosed Himself to him, and is known by him, as such... he loves because God loves, and loves him.

Bradshaw (1994) takes this further and illustrates the practical application of agape love in nursing care. According to Bradshaw, whilst the spiritual dimension is the essence of a person, it is not differentiated from one's physicality or psychology and is inextricably in relationship with God. This is biblically portrayed as a covenant relationship based on love and it is this agape which is the motive underlying the concept of care. It is held that this is the mode by which human beings express God's purposes within society, and so, according to Bradshaw, may be described as the basis for health care. In regard to this, Bradshaw (1994) concludes, "herein lies its relevance for nursing" (p. 17).

\subsection{Limitations of Christian theological position in health care}

The position on Christian theological tradition, as advanced by Bradshaw (1994), Richardson (1969a, 1969b), Berkhof (1979), Shelley and Fish (1988) and Carson (1989) illustrates well its connection and significance to nursing. However, such a stance limits spirituality to being a specifically Christian phenomenon. It may lead to the misconception that spirituality is equated with Christianity, hence, restricting reference to the spiritual dimension and its practicalities to the context of Christian patients. Notwithstanding the fact that Christian theologians from the time of Schleiermacher (1799) onwards have specifically recognized spiritual awareness as a human phenomenon I find it necessary to transcend any one religious tradition, in considering spirituality as a universal function of humanity. For example, there is evidence to suggest that eastern religions have well developed spirituality (Stace, 1960; Parrinder, 1968; Fellow, 1978). Hinduism has evolved following the influences of Hindu philosophers such as Shankara in early ninth century AD who taught a strict nondualism (A-dvita) or monism. Two centuries later Ramanuja proposed a 'qualified nondualism' or 'difference nondifference' between divine and human, seeking to allow devotion to the neuter Brahman personalized as Vishnu.

Later Madhva came to espouse the notion of frank dualism (dvita) of God and souls. The Sankhya (enumeration) philosophy early in the Christian era propounded a dualism of spirit and nature (purusha and prakin) which came to merge with Yoga as theory for its practice. Salvation could be achieved by self discipline but also by deep devotion to the Lord (Ishvara) who was a divine example. The influence of Hindu spirituality must not be undermined as several other religions have evolved from this, for example, Buddhism, Sikhism and Jainism as practiced by some people in Britain. However, spirituality needs to be considered beyond the realms of religions and one promising perspective is that of modern empirical research into spiritual awareness.

\section{The biological basis of spirituality}

Research over the past 20 years suggests that spiritual awareness may be a human universal, hence in 
Table 1

Positive responses to questions about religious experience in 11 national surveys (Source: Hay, 1994, p. 7)

\begin{tabular}{|c|c|c|c|c|}
\hline Survey & Publication date & Country & Sample size & Percentage claiming experience \\
\hline \multirow[t]{4}{*}{ Back and Bourque (Gallup) ${ }^{\mathrm{b}}$} & $1970^{\mathrm{a}}$ & US & & \\
\hline & (1962) & & 3232 & 20.5 \\
\hline & (1966) & & 3518 & 32.0 \\
\hline & (1967) & & 3168 & 41.0 \\
\hline Greeley $(\mathrm{NORC})^{\mathrm{e}}$ & 1975 & US & 1467 & 35.0 \\
\hline Hay and Morisy (1978) & 1978 & $\mathrm{UK}$ & 1865 & 36.0 \\
\hline NOP & & & & 31.0 \\
\hline Gallup $^{\mathrm{b}}$ & 1978 & US & 3000 & 31.0 \\
\hline PRRC $^{\mathrm{d}}$ & 1978 & US & 3062 & 35.0 \\
\hline Morgan Research ${ }^{\mathrm{c}}$ & 1983 & Australia & 1228 & 44.0 \\
\hline AHRC/Gallup ${ }^{\mathrm{e}}$ & $1985 \mathrm{a}$ & UK & 1030 & 33.0 \\
\hline AHRC/Gallup ${ }^{\text {e }}$ & $1985 b$ & US & 1525 & 43.0 \\
\hline Hay and Heald (1987) (Gallup) & 1987 & UK & 985 & 48.0 \\
\hline
\end{tabular}

${ }^{a}$ The article published in 1970 reviewed surveys in 1962, 1966 and 1967.

${ }^{\mathrm{b}}$ Responses to Hardy's question.

c Responses to Greeley's question.

d Princeton Religion Research Centre.

e Alister Hardy Research Centre.

tune with the universalistic assumptions of the Enlightenment. The hypothesis of the zoologist A. Hardy (1979) is that religious awareness, or spirituality, is natural to the human species and has evolved because it has biological survival value. D. Hay (1994) provides a comprehensive review of Hardy's hypothesis in the light of subsequent studies on spiritual experiences. The salient points are drawn from this review to develop a notion of spirituality as biological phenomenon.

As a committed evolutionist with an empirical scientific background, Hardy related his notion of religious experience to those of the account of Otto (1950) of 'numinous', that is, a direct awareness of a sacred or divine presence. As Otto's work had been pivotal in the development of the biological hypothesis of spirituality, his ideas are discussed briefly here. Otto advanced the notion of numinous as a central theme in his book 'The idea of the Holy'. In essence, he made four claims in his analysis of religion. These are as follows:

1. Religious experience is a distinctive kind of experience.

\footnotetext{
${ }^{1}$ The word being derived from the Latin numen meaning divinity or power implicit in a sacred place or object.
}

2. There is no religion in which religious experience does not live as its 'real innermost core'.

3. We can talk about religious experience, but we must do so obliquely and by means of metaphors.

4. Religious experience is of something, or least so it feels and this something is the numinous ${ }^{1}$.

Hay (1994) notes that this is quite different from a theoretical belief being more akin to a perception. Such experience, according to Hardy (1979), is natural. However, he did not limit the numinous awareness to the overwhelming experience of the "mysterium tremendum et fascinans' that Otto (1950) describes, believing it to be a relatively frequent and even commonplace part of human experience.

Hardy defended his conjecture by drawing from the fields of psychology, animal behavior, psychic research and anthropology (Hay, 1994). Referring to the work of the French, Victorian and Edwardian anthropologists he attempted to provide empirical evidence that some awareness of the sacred is more or less universally reported in the human species. Hardy's hypothesis led to further studies on spiritual awareness in this country and abroad. These studies were carried out, using questions (see below) which operationalized definitions of numinous (Otto, 1950) or mystical (James, 1902; Stace, 1960) experience. 


Have you ever as an adult had the feeling that you were somehow in
the presence of God? (Glock and Stark, 1965)
Would you say that you ever had a 'religious or mystical experience'-
that is, a moment of sudden religious insight and awakening? (Back
and Bourque, 1970; Gallup Poll data)
Have you ever felt as though you were very close to a powerful
spiritual force that seemed to lift you out of yourself? (Greeley,
1975)
Have you ever felt you were in close contact with something holy or
sacred? (Wuthnow, 1976)
wave you ever been aware of or influenced by a presence or a power,
self? (Hay and Morisy, 1978)

Between 1970 and 1987, positive response rates were reported for a series of national surveys conducted in the US, UK and Australia respectively, as given in Table 1 .

It will be noted that the 1987 British national survey suggests that almost half of the British adult population believe they have been spiritually or religiously aware, at least from time to time. In the light of other findings from in-depth studies (Hay and Morisy, 1978; Hardy, 1979; Lewis, 1985), Hay (1994) suggests that, where there is the opportunity to build trust, this figure is boosted to about two thirds of the population. Hay (1990) illustrates the kinds of experiences most British people intimately know, whether they are formally religious or not:

- Being aware of an emergent unfolding pattern of life, not imposed by themselves, that links them in a meaningful way with the rest of reality;

- Being aware of the presence of God, typically in a way that helps them to relate creatively to the social context in which they find themselves;

- Feeling a unifying presence in nature;

- Feeling at one with or not different from the rest of reality.
Hay (1994) considers all of these experiences to be forms of spirituality. That is, being aware of oneself in an holistic relationship with the rest of reality, which in specifically religious experience in Western population usually implies an awareness of God.

\subsection{Limitations of the biological theory of spirituality}

However, there exists criticisms of the biological theory of spirituality as well as Otto's idea of the numinous. According to N. Smart (1964) Otto attempts to give an analysis of religious thoughts and experience as distinct forms of human experience and that religion springs from a certain kind of experience, i.e 'numinous experience'. "This apprehension is experience of the holy in the primary datum in religion, and the theological ideas are secondary to it" (Smart, 1964, p. 132). Otto's analysis of the numinous experience in terms of the Latin phrase "mysterium tremendum et fascinans': what is apprehended is a mystery which is awe-inspiring and fascination. Although Otto's idea illuminates an important type of religious experience, Smart points out the he has not adequately represented the nature of mysticism, i.e, the quest, through contemplation, of inner insight and peace. The latter points are identified as central to spirituality. However, Smart acknowledges the plausibility of Otto's claim that the numinous is central everywhere in religion, i.e. the numinous and mystical strands of experience and language are here brought together in a single unifying doctrine. Religious experience has its own kind of logic and no one has illustrated this better than Otto. Although the 'Idea of the Holy' was not always well understood, it communicated directly to the intellectuals of the twentieth century, and laid the foundation for much later work (see Hardy (1979) and Hay (1987)) in this area of personal religious experience and mysticisms.

The other major criticism of experiential and biological theories of spirituality comes from Lindbeck (1984). He asserts that a cultural linguistic approach is much more preferable to these traditions in that this alternative is consonant with anthropological, sociological and psychological studies. In this regard religions and expressions of their spirituality are viewed as comprehensive interpretive schemes, usually embodied in myths or narratives and overtly ritualized, which structure human experience and understanding of itself and the world. The pervasive nature of a religion is as such that it exercises influence in the way people experience themselves and their world even when it is no longer explicitly adhered to. To put it another way, a religion can be regarded as a form of cultural and/or linguistic framework or medium that shapes the 
entirety of life and thought. Lindbeck (1984, p. 32) writes:

It functions somewhat like a Kantian priori, although in this case the 'a priori' is a set of acquired skills that could be different. It is not primarily an array of beliefs about truth and the God (though it may involve these), or a symbolism experience of basic attitudes, beliefs or sentiments (though these will be general).

Lindbeck argues that, like a culture or language, it is communal phenomena that shapes the subjectivities of individuals rather than primarily a manifestation of those subjectivities. It comprises a vocabulary of discursive and nondiscursive symbol together with a distinct logic as a grammar in terms of which this vocabulary of religion or a cultural linguistic system because the relation of religion and experience is dialectal and not unilateral. Lindbeck takes the view that religion produces experiences, for which the causalities are reciprocal and this stance obviously questions the plausibility of experiential approaches based on biological theory.

\section{Implications for nursing}

However, the continuing evidence of the impact of spiritual experiences upon individuals as suggested by Otto (1950), James (1902), Stace (1960), Hardy (1979) and Hay (1987) militates against Lindbeck's criticisms. According to Hay (1987) research studies have consistently suggested that people who claimed to have undergone spiritual experience, compared with those who do not report such experience appear to be:

- calmer and more stable

- able to find more meaning in their lives

- more concerned with issues of social justice

- more tolerant of others

- less materialistic

- less status conscious

- less likely than others to be racially prejudiced

These studies have further implications of specific importance for nursing. Hay's qualitative research reveals that people often experienced an intensity of spiritual awareness when they were undergoing stress related to emotion, physical illness or other forms of crisis. These experiences often remain a personal secret because of the fear that if others found out, they may become the subject of ridicule, be considered stupid or even mad (Hay, 1987). According to Hay (1996, p. 134),

Quite often the initial breadth of a person's insight into God's presence dwindles and becomes constricted to little more than a source of private comfort in times of distress. This is to diminish spirituality.

However, even this privatized spirituality may be further constricted because the patient is unable to utilize its positive or healing aspects, through fearfulness or inability of the nursing staff to integrate it into the patients total care. It is highly likely that patients may trivialize or suppress their spiritual awareness if nurses appear to be unaware of these experiences or remain insensitive to patients' spiritual needs.

At present the biological hypothesis that Hardy and Hay propose is relatively unknown in the literature on nursing. Because of this unawareness the descriptions of spirituality currently used in nursing literature do not embrace its biological root as identified in the research of Hardy (1979) and subsequent studies (Hay, 1994). In the light of this inadequacy and to restore the missing link, an operational definition of spirituality embracing its biological root is provided in the next section.

\section{Operational definition of spirituality}

As suggested earlier, the data from the Hay (1994) and similar studies indicate that there is a basis to propose that the biological nature of individuals is such that their spirituality, as manifested in the forms examined earlier, comes into focus when the person faces emotional stress, physical illness or death. Presently, the nursing literature on the biological basis of spirituality, as hypothesized by Hay and Hardy, is nonexistent in nursing. To take an entirely holistic view of spirituality requires that its biological root should be embraced as well.

In this paper an holistic definition of spirituality, incorporating its biological root, is operationalized as follows:

Spirituality is rooted in an awareness which is part of the biological make up of the human species. Spirituality is present in all individuals and it may manifest as inner peace and strength derived from perceived relationship with a transcendent God or 
an ultimate reality or whatever an individual values as supreme.

The spiritual dimension evokes feelings which demonstrate the existence of love, faith, hope, trust, awe and inspirations; therein providing meaning and a reason for existence. It comes into focus particularly when an individual faces emotional stress, physical illness or death.

\section{Summary and conclusion}

In this paper the current understanding of spirituality in the literature on nursing was reviewed. It emerged that if spirituality is discussed at all, it is usually in the context of an holistic notion of the human person and from the perspective of Christian theological tradition. Evidence is put forward to suggest that consideration should be given to the biological basis of spirituality. Presently, this is lacking in the literature on nursing.

Because of this limitation, a more satisfactory proposal would be that spirituality should be seen from a broad perspective, including its biological root, for the following reasons: firstly, spirituality as a need comes into focus in illness when the sufferer faces emotional stress, physical distress or death; secondly, both religious and nonreligious persons (atheists and agnostics) may express spiritual needs, in the sense of a need for meaning and purpose, identity, or a sense of harmonious interconnectedness. Finally, it is hoped that this review paper has added to the developing nursing paradigm of spirituality.

\section{References}

Barth, K., 1958. In: Church Dogmatics, vol. 3/1. T\&T Clark, Edinburgh Bromiley, G. and Torrance, T., Trans.

Berkhof, H., 1979. An Introduction to the Study of the Christian Faith. Berdmans, Grand Rapids.

Bradshaw, A., 1994. Lighting the Lamp: the Spiritual Dimension of Nursing Care. Scutari Press, London.

Carson, V.B., 1989. Spiritual Dimensions of Nursing Practice. B Saunders Company, Philadelphia.

Colliton, M., 1981. The spiritual dimension of nursing. In: Belland, E., Passos, J.Y. (Eds.), Clinical Nursing. Macmillan, New York.

Fellow, W., 1978. East and West. Rinehart and Winston, New York.

Gallup Poll, 1978. Religion in America: the Gallup Opinion Index 1977-1978. American Institute of Public Opinion, Princeton.
Granstrom, S.L., 1985. Spiritual nursing care for oncology patients. Topics in Clinical Nursing 7 (1), 39-45.

Hardy, A., 1979. The Spiritual Nature of Man. Clarendon Press, Oxford.

Hay, D., Morisy, A., 1978. Reports of ecstatic, paranormal or Religious experience in Great Britain and the United States: A comparison of trends. Journal for the Scientific Study of Religion 17 (3), 255-268.

Hay, D., Heald, G., 1987. Religion is good for you. New Society $80,20-22$.

Hay, D., 1987. Exploring Inner Space: Scientist and Religious Experience. Mowbray, London.

Hay, D., 1990. Religious Experience Today. Mowbray, London.

Hay, D., 1994. On the biology of God: what is the current status of Hardy's hypothesis? International Journal for the Psychology of Religion 4 (1), 1-23.

Hay, D., 1996. Morals and religion. The Tablet 3, 132-133.

Hebblewaite, B., 1981. The Adequacy of Christian Ethics. Marshall, Morgan and Scott, London.

James, W., 1902. The Varieties of Religious Experience. The Fontana Library, London.

Lazlo, E., 1972. Introduction to Systems in Philosophy. Gordon and Breach, London.

Lindbeck, G.A., 1984. The Nature of Doctrine. Westminster Press, Philadelphia.

Legere, T., 1984. A spirituality for today. Studies in Formative Spirituality 5 (3), 375-385.

Lewis, D., 1985. All in good faith. Nursing Times, March 18/ 24, 40.

Mische, P., 1982. Toward a global spirituality. In: Mische, P. (Ed.), the Whole Earth Papers. Global Education Association, East Grange, NJ No. 16.

Murray, R., Zentner, J.P., 1989. Nursing Concepts for Health Promotion. Prentice Hall, London.

Nygren, A., 1938. In: Agape and Eros, vol. 1. SPCK, London.

Otto, R., 1950. The Idea of the Holy. University Press, Oxford.

Parrinder, G., 1968. Asian Religions. Sheldon Press, London.

Popkin, R.H., Stroll, A., 1993. Philosophy. Butterworth, England.

Richardson, A., 1969a. Love. In: Richardson, A. (Ed.), A Dictionary of Christian Theology. SCM Press, London, p. 200.

Richardson, A., 1969b. Spiritual healing. In: Richardson, A. (Ed.), A Dictionary of Christian Theology. SCM Press, London, p. 328.

Schleiermacher, F., 1799. On Religion: Speeches to its Cultured Despiser. Harper Torchbooks, New York (Translated by John Oman and with an introduction by Rudolf Otto).

Shelley, A.L., Fish, S., 1988. Spiritual Care: the Nurses Role. Inter Varsity Press, IL.

Smart, N., 1964. The Religious Experience of Mankind. Collins, London.

Smutts, J.C., 1926. Holism and Evolution. Macmillan, New York.

Soeken, K.L., Carson, V.J., 1987. Responding to the spiritual needs of the chronically ill. Nursing Clinics of North America 22 (3), 603-611. 
Stace, W.T., 1960. Mysticism and Philosophy. Lippincott, London.

Stallwood, J., 1981. Spiritual Dimensions of Nursing Practice. In: Belland, I.L., Passos, J.Y. (Eds.), Clinical Nursing. Macmillan, New York.
Stoll, P.G., 1989. The essence of spirituality. In: Carson, V. (Ed.), Spiritual Dimensions of Nursing Practice. W.B Saunders, Philadelphia, pp. 4-23.

Warburton, N., 1992. Philosophy: the Basics. Routledge, London. 